\title{
EVALUASI KEBIJAKAN TATA NASKAH DINAS DI UNIVERSITAS LANCANG KUNING
}

\author{
Ermina Sari, Surya Dailiati dan Trio Saputra \\ Universitas Lancang Kuning \\ Email : surya-dailiati@unilak.ac.id
}

\begin{abstract}
This study aims to examine the official script in the environment of universitas lancang kuning, making the manuscript format of the paper work aliralur script of the service as needed, this study was lifted from the existing phenomenon in the universitas lancang kuning that has no provision in making the official script, this study using the method qualitative descriptive research, which is available or builds a unity or explains the meaning behind reality. Researchers are based on the reality or ongoing events in the field. Furthermore, researchers will explore further phenomena that occur.

The results show that the implementation of the official script has not been effective because the regulations on the official script of the universitas lancang kuning environment has no legal umbrella. a recommendation that would be taken into consideration in the improvement of grammar is that the university should immediately issue a policy on the legal document. In order for performance in each unit can be increased and avoided from overlapping authority. As well as candy and research about the official script can be a reference in the regulation of yellow university environment, because simply in the provisions have been described the official script of the manufacture of symbols, heads of departments, examples of making official script, stamp and format disposition sheet.
\end{abstract}

Keywords: official script, university, evaluation

\section{Abstrak}

Penelitian ini bertujuan untuk menelaah tata naskah dinas di lingkungan universitas lancang kuning, Membuat standar format naskah dinas dan membuat bagan aliralur naskah dinas sesuai kebutuhan, penelitian ini diangkat dari fenomena yang ada di universitas lancang kuning yang belum terdapat aturan dalam pembuatan naskah dinas, Penelitian ini menggunakan metode penelitian deskriptif kualitatif, yang bertujuan menggali atau membangun suatu proporsi atau menjelaskan makna di balik realita. Peneliti berpijak dari realita atau peristiwa yang berlangsung di lapangan. Selanjutnya, peneliti akan mendalami lebih jauh fenomena yang terjadi.

Hasil penelitian menunjukkan Pelaksanaan tata naskah dinas belum efektif karena aturan tentang tata naskah dinas dilingkungan universitas lancang kuning belum ada payung hukum. rekomendasi yang sekiranya dapat dijadikan bahan pertimbangan dalam melakukan perbaikan pelaksanaan tata naskah dinas adalah Universitas harus secepatnya mengeluarkan kebijakan tentang naskah dinas yang berbadan hukum. Agar kinerja di masing-masing unit dapat meningkat dan terhindari dari tumpang tinding kewenangan. Serta permen ristek dikti tentang tata naskah dinas bisa menjadi acuan dalam membuat aturan dilingkungan universitas lancang kuning, karena secara rinci didalam aturan tersebut telah menjelaskan naskah dinas dari pembuatan lambang, kepala naskah dinas, contoh pembuatan naskah dinas, cap dan format lembar disposisi.

Kata Kunci : tata naskah dinas, universitas, evaluasi 


\section{PENDAHULUAN}

Naskah dinas merupakan sarana komunikasi tertulis yang dirumuskan dalam suatu format tertentu digunakan untuk kepentingan pelaksanaan tugas dan fungsi organisasi. Pentingnya naskah dinas untuk keseragaman tata kelola naskah dinas di lingkungan organisasi. Disamping itu, naskah dinas salah satu komponen penting dalam administrasi umum, setiap organisasi harus mempunyai standar baku dalam pembuatan naskah dinas, karena ini akan menjadi alat komunikasi dalam penyelenggaraan suatu kegiatan yang ada didalam lingkungan organisasi, bentuk dari naskah dinas yang baku menjadikan acuan umum dan menghindarkan tumpang tindih kewenangan pejabat dalam pelaksaan tugas didalam organisasi.

Naskah dinas dalam bentuk surat bukan hanya sekedar alat komunikasi tapi juga mempunyai fungsi sebagai alat bukti tertulis, alat pengingat, bukti historis dan pedoman kerja yang sangat penting bagi organisasi, baik pemerintah maupun swasta. Kegiatan komunikasi menciptakan hubungan antara satu pihak dengan pihak lainnya melalui kegiatan surat-menyurat. Komunikasi dilakukan melalui proses baik yang secara internal maupun eksternal. Komunikasi yang internal maupun eksternal berjalan efektif, jika adanya pemahaman, kesepakatan antara kedua belah pihak baik pengirim maupun penerima. Oleh karena itu komunikasi efektif, jika dilakukan secara dua arah yaitu pengirim mengirim suatu pesan dan penerima memahami dan memberikan umpan balik terhadap pesan yang dikirim. Melihat gambaran diatas, nampak bahwa kenyataan kegiatan surat menyurat yang terkait dengan tata naskah merupakan kegiatan yang vital dan dilakukan secara integrasi dari seluruh kegiatan organisasi. Tata naskah dinas dapat dilaksanakan secara efektif, karena itu harus dapat merancang dan mengatur bentuk dan susuna surat, ukuran, kualitas kertas surat. Jika pengaturan dan perancangan dipersiapkan sejak tahap awal dari hidup arsip, maka dapat mempermudah dalam penyimpanan dan penemuan kembali arsip dan penetapan saran atau peralatan untuk penyimpananya (Usman et al., 2010)

Universitas sebagai lembaga pendidikan merupakan organisasi yang menjadi acuan dalam pengembangan ilmu dan teknologi,tantangan ini menjadikan kompleksitas kegiatan harus berjalan dengan baik, dan terdokumentasi secara teratur dan terciptanya keseragaman baik pada tingkat universitas maupun fakultas. Bukan hanya untuk kepentingan publik tapi juga untuk kepentingan perguruan tinggi untuk berkomunnikasi secara internal dilingkungan universitas maupun secara eksternal.

Di lingkungan Universitas Lancang Kuning administrasi umum menjadi penunjang dan penilaian bagi perguruan tinggi dalam menjalankan kegiatan, pentingnya aturan yang standar dalam pengolaan naskah dinas diperguruan tinggi agar berjalan komunikasi secara efektif dan efisien. Naskah dinas merupakan bagian dari administrasi umum, dimana naskah dinas tersebut terbagi menjadi beberapa jenis. Untuk lebih jelas jelasnya mengenai jenis-jenis naskah dinas dapat dilihat pada tabel berikut ini:

Tabel 1. Jenis-jenis Naskah Dinas

\begin{tabular}{|c|l|l|}
\hline No & \multicolumn{1}{|c|}{ Jenis naskah dinas } & \multicolumn{1}{c|}{ Terdiri } \\
\hline 1 & Naskah dinas pengaturan & 1.peraturan \\
& & 2.surat edaran \\
& & 3.prosedur oprasional standar \\
\hline 2 & Naskah dinas penetapan & 1.instruksi \\
& & 2.surat perintah \\
& & 3.surat tugas \\
\hline 3 & Naskah dinas penugasan & 1.nota dinas \\
& & 2.memo \\
& & 3. surat dinas \\
\hline
\end{tabular}




\begin{tabular}{|c|l|l|}
\hline & & 4.surat undangan \\
\hline 4 & Naskah dinas korespondensi & 5.surat pengantar \\
& & 1.nota kesepahaman \\
& & 2.perjanjian kerja sama \\
& & 3.surat kuasa \\
& & 4.berita acara \\
& & 5.surat keterangan \\
& & 6.surat pernyataan \\
& & 7.pengumuman \\
\hline 5 & Naskah dinas khusus & 8.laporan \\
& & 9.natula \\
\hline 6 & & 1.instruksi \\
& & 2.surat perintah \\
\hline
\end{tabular}

Sumber: Permen Ristek Dikti, 2015

Dari tabel diatas dapat dilakukan infentarisasi jenis naskah dinas digunakan dilingkungan Universitas Lancang Kuning dalam rangka untuk menjalin komunikasi dan sebagai dokumentasi suatu kegiatan atau program. Hal ini menunjukkan pentingnya pengaturan naskah dinas dalam jenis format, penyiapan dan distribusi dalam melaksanakan kegiatan, untuk penyeragaman dilingkungan universitas. Sampai saat ini Universitas Lancang Kuning belum memiliki acuan dalam pembuatan naskah dinas. Menurut Nugroho (2010:471), sebuah kebijakan publik tidak bisa dilepas begitu saja. Kebijakan harus diawasi, dan salah satu mekanisme pengawasan tersebut" evaluasi kebijakan". Evaluasi biasanya ditujukan untuk menilai sejauh mana keefektifan kebijakan publik guna dipertanggung jawabkan kepada konstituennya. Sejauh mana tujuan dicapai. Untuk lebih jelasnya mengenai fenomena-fenomena tersebut akan dijelaskan berikut ini: (1) Pelaksanaan format naskah dinas di lingkungan Universitas Lancang Kuning belum memiliki acuan yang baku di setiap unit kerja pada tingkat rektorat, fakultas dan prodi. (2) Naskah dinas yang digunakan belum mempunyai format yang baku dan dan belum pernah dievaluasi penggunaannya. (3) Penggunaan naskah dinas yang berhubungan dengan penggunaan dana belum memiliki acuan untuk menentukan besaran dana, hak dan kewajiban, dan pengaturan waktu pelaporan. (4) Sistim administrasi pengasipan naskah belum berstandar, dan belum pernah dievaluasi. Berdasarkan fenomena-fenomena diatas perlu melakukan kajian dengan judul "Evaluasi Kebijakan Naskah Dinas Di Lingkungan Universitas Lancang Kuning”.

\section{METODE}

Penelitian ini menggunakan metode penelitian deskriptif kualitatif, yang bertujuan menggali atau membangun suatu proporsi atau menjelaskan makna di balik realita. Peneliti berpijak dari realita atau peristiwa yang berlangsung di lapangan. Selanjutnya, peneliti akan mendalami lebih jauh mengapa fenomena itu terjadi (Moleong, 2010: 36). Dalam penelitian kualitatif ini, peneliti berusaha mengembangkan konsep dan menghimpun fakta dengan cermat tanpa berusaha melakukan hipotesis. Sedangkan penelitian deskriptif bertujuan untuk menggambarkan realitas sosial yang kompleks dengan menerapkan konsep-konsep yang telah dikembangkan (Sugiyono, 2012: 72) dalam administrasi publik. 
Jadi penelitian kualitatif-deskriptif adalah penelitian yang dilakukan untuk mendeskripsikan secara terperinci mengenai evaluasi kebijakan tata naskah dinas di universitas lancang kuning.

Analisis data adalah proses menyusun dan menggabungkan data ke dalam pola, tema, kategori, sedangkan penafsiran adalah memberikan makna kepada analisis, menjelaskan pola atau kategori, dan mencari hubungan antara beberapa konsep. Penafsiran menggambarkan perspektif peneliti bukan kebenaran. Analisis dan penafsiran data dalam penelitian kualitatif pada dasarnya bukan merupakan hal yang berjalan bersama, keduanya dilakukan sejak awal penelitian. Analisis data dilakukan agar data yang telah diperoleh akan lebih bermakna. Analisis data merupakan proses penyederhanaan data kedalam bentuk yang lebih mudah dibaca dan di interprestasikan. Miles dan Huberman (1992: 20) menjelaskan analisis data adalah proses mencari secara sistematis dan mengatur catatan wawancara, catatan lapangan, dan rider lain yang dihimpun untuk menggiring pengertian. Analisis tersebut melibatkan kerja dengan data, mengaturnya, memisahkan kedalam unit-unit yang dapat dikelola, memadukannya, mencari-cari pola memenuhi hal-hal penting dan apa yang diketahui dan memutuskan apa yang akan disampaikan kepada orang lain.

\section{HASIL DAN PEMBAHASAN}

Berdasarkan permenristek dikti No.20 tahun 2015 tentang tata naskah dinas di perguruan kementrian riset dan teknologi dan pendidikan tinggi menjelaskan pembuatan aturan naskah dinas dari kewenangan pejabat yang mengeluarkan naskah dinas sampai berbentuk teknis dalam pembuatan naskah dinas, itu semua telah diatur dengan sangat rinci dalam tata naskah dinas tersebut.

Dengan dibentuknya perguruan tinggi, perlunya aturan tentang tata naskah dinas dilingkungan perguruan tinggi, sebagai informasi tertulis, alat komunikasi kedinasan yang dibuat dan/atau dikeluarkan oleh pejabat yang berwenang di lingkungan perguruan tinggi. Pada dasarnya Tata naskah dibuat untuk pengelolaan informasi tertulis yang meliputi pengaturan jenis, format, penyiapan, pengamanan, pengesahan, distribusi, dan penyimpanan naskah dinas, serta media yang digunakan dalam kedinasan.

Kebijakan naskah dinas di lingkungan universitas lancang kuning pada saat ini dilihat belum adanya pedoman baku dalam standar pengeluaran surat menyurat dari pejabat di lingkungan universitas, lemahnya pengolaan informasi tertulis ini mengakibatkan sebagian pejabat masih binggung dalam mengeluarkan surat untuk kebutuhan kedinasan, serta dalam evaluasi yang dilakukan oleh penjamin mutu universitas belum menyentuh aspek subtansial dalam pengaturan naskah dinas.

Hal yang menjadi hambatan dalam naskah dinas ini belum adanya aturan dan kebijakan dari rektor tentang tata naskah dinas di lingkungan universitas lancang kuning, aspek legal aturan ini harus dibuat untuk dapat diberlakukan di lingkungan kerja universitas, tanggung jawab setiap pejabat terjamin dengan adanya aturan ini.

Peraturan kemtrian ristek dikti dalam hal ini yang akan menjadi acuan peneliti dalam melakukan evaluasi naskah dinas di universitas lancang kuning, temuan yang ada dari semua unit menunjukkan adanya perbedaan dalam mendistribusikan naskah dinas. Untuk itu aturan di universitas lancang kuning butuh diseragamkan dengan aturan yang ada dari dikti, untuk kelancaran kinerja dan pembuatan aturan yang legal.

Pembahasan penelitian ini, merujuk pada teori yang dikemukakan oleh Bridgman \& Davis, Crossfield \& Byrner, dan Badjuri \& Yuwono (2002). Berdasarkan rujukan tersebut terdapat empat aspek yang akan dikaji dalam penelitian ini. Keempat aspek tersebut yakni : Pertama, input dengan mengamati (a) sumberdaya pendukung dan bahan-bahan dasar yang diperlukan untuk melaksanakan kebijakan; (b) Sumber daya manusia, uang atau infrastruktur pendukung lain yang diperlukan. Kedua, proses dengan 
mengamati (a) kebijakan ditransformasikan dalam bentuk pelayanan kepada steakholder; (b) efektivitas dan efesiensi dalam pelaksanaan kebijakan. Ketiga, hasil dengan mengamati (a) hasil atau produk yang dihasilkan sebuah kebijakan publik; (b) berapa orang yang berhasil mengikuti program atau kebijakan. Keempat, dampak dengan mengamati (a) dampak yang diterima oleh stekholderatau pihak yang terkena kebijakan; (b) dampak positif dan negatif dari kebijakan.

1. Input, yaitu diamati dari gejala :

a. sumberdaya pendukung dan bahan-bahan dasar yang diperlukan untuk melaksanakan kebijakan

Peraturan Tentang Tata naskah dinas di lingkungan universitas lancang kuning.Sumber daya yaitu semua potensi yang dimiliki untuk melaksanakan pekerjaan sesuai dengan bidang tugasnya secara berhasil guna dan berdaya guna sesuai dengan ketentuan yang berlaku. Sumber daya pendukung dan bahan-bahan dasar yang diperlukan dalam melaksanakan kebijakan Peraturan Tentang Tata Naskah Dinas melalui sosialisasi kepada semua pegawai dan membuat buku pedoman Peraturan Rektor tentang tata naskah dinas.

Sumber daya pendukung semuanya mencukupi baik di bidang masing-masin di universitas lancang kuning. Selaku Penanggung Jawab pelaksanaan kebijakan di universitas, dalam segi sarana dan prasarana sangat mencukupi, alokasi anggarannya sangat mencukupi, untuk pengolahan data sudah tersedia komputer yang jumlahnya memadai lengkap dengan printernya.Penulis menyimpulkan bahwa ketersediaan sumber daya pendukung dan bahan-bahan dasar yang diperlukan untuk melaksanakan kebijakan Peraturan tentang tata naskah dinas tergolong cukup. Dengan demikian tidak adanya masalah pada tahap ini.

b. Sumber daya manusia

Sumber daya manusia yang ikut terlibat dalam kebijakan Peraturan Rektor tentang naskah dinas sebagaian besar adalah pejabat unit/lembaga dengan diabntu petugas teknis seperti staf tata usaha/operator. Dari tingkat pendidikan seluruh pegawai yang terlibat denga naskah dinas merupakan pegawai yang memiliki kemampuan mengoprasikan komputer. Data menunjukkan bahwa $60 \%$ pegawai yang diteliti memiliki pendidikan Strata satu. Data pendidikan pegawai Universitas Lancang Kuning dapat dilihat dalam tabel dibawah ini.

Tabel 2. Pendidikan pegawai Universitas Lancang Kuning

\begin{tabular}{|l|l|l|}
\hline UNIT/LEMBAGA & NAMA PEGAWAI & Pendidikan Formal \\
\hline \multirow{4}{*}{ LPPM } & Suyanto Ds.SH.MH & S1 \\
\cline { 2 - 3 } & Zurhema, S.Hut & S1 \\
\cline { 2 - 3 } & Elmi, SE & S1 \\
\hline BPM & Novri Hariawan, S.Kom & S1 \\
\hline BHE & Suwito,S.hum & S1 \\
\hline Perpustakaan & Ermanilis, S.IP & S1 \\
\hline & Adroriadin.A.Ma & D3 \\
\hline & Rustam & \\
\hline & Zuliati, S.IP & S1 \\
\hline & Yeni Handayani, S.IP & S1 \\
\hline & Hara Fadhillah & \\
\hline & Putri Novianti,SIP & S1 \\
\hline
\end{tabular}

Berdasarkan pendidikan, sumber daya manusia yang ada di lingkungan Universitas Lancang Kuning cukup berkompeten dibidang pendidikan formal tetapi masih banyak juga yang masih berpindidikan rendah dibawah S1 sebanyak 40\%. Sedangkan jika dilihat dari Sumber Daya Pimpinan 
lembaga/unit menunjukkan bahwa pimpinan memiliki kompetensi yang memadai. Pendidikan yang baik akan memudahkan bagi pimpinan untuk mengonsep, mengecek dan memperbaiki naskah dinas. Hal ini akan mampu menjadi asset dalam memperkuat sumber daya manusia yang mendukung terlaksananya kebijakan Peraturan Rektor Tentang Tata Naskah dinas. Data pejabat pimpinan lembaga dapat dilihat dalam tabel dibawah ini.

Tabel 3 Pendidikan Pimpinan Lembaga di lingkungan Universitas Lancang Kuning

\begin{tabular}{|c|c|c|}
\hline No & Unit Lembaga & Pedidikan Pimpinan \\
\hline 1 & LPPPM & S3 \\
\hline 2 & BPM & S2 \\
\hline 3 & BHE & S2 \\
\hline 4 & Perpustakaan & S2 \\
\hline
\end{tabular}

Penulis menemukan beberapa hal terkait pemahaman Sumber daya mengenai naskah dinas, yaitu a.Sumber daya belum Mewujudkan tertib administrasi pemerintahan.

b.Mendukung kelancaran komunikasi tertulis pada pemerintah pusat dan daerah.

c.Ketentuan yang ada belum sepenuhnya efektif di implementasikan

d.Penyelenggaraan tata naskah dinas di lingkungan instansi pemerintah belum terpadu

2. Proses, yang diamati dari gejala :

a. kebijakan ditransformasikan dalam bentuk naskah dinas kepada steakholder

Berdasarkan tujuan tata naskah dinas untuk pedoman pelaksanaan kebutuhan kedinasan dan mengakomodir kebijakan/regulasi yang memberikan kontribusi besar terhadap kedinasan untuk mengakomodasi kepentingan para pemangku kepentingan di dunia pendidikan juga sebagai bentuk tranparansi. Harapannya dengan adanya tata naskah dinas untuk pengelolaan informasi tertulis yang meliputi pengaturan jenis, format, penyiapan, pengamanan, pengesahan, distribusi, dan penyimpanan naskah dinas, serta media yang digunakan dalam kedinasan.

b. efektivitas dan efesiensi dalam pelaksanaan kebijakan

William N Dunn (1999:610) mengatakan bahwa Efektivitas berarti apakah hasil yang diinginkan telah dicapai. Sedangkan efisien berarti seberapa banyak usaha diperlukan untuk mencapai hasil yang diinginkan. Efektivitas naskah dinas di lingkungan universitas lancang kuning dilihat dari hasil observasi ditemukan belum adanya format baku dalam membuat naskah dinas. Penulis mencermati harus adanya pembaruan dalam pembuatan naskah dinas, dan membuat aturan yang legal untuk mempercepat sosialisasi agar adanya terstandarisasi naskah dinas di setiap unit. Dari data di 13 unit di universitas terlihat naskah dinas belum tersimpan dengan baik, masih terdapat penyimpanan dokumen tahun yang lalu sulit dicari, hal ini menandakan pengelolaan naskah dinas yang belum baik dan format dalam penulisan berita acara yang berbeda-beda dalam setiap unit kerja.

Efisiensi Naskah Dinas dilingkungan univeritas lancang kuning dapat dilihat dari seberapa banyak usaha diperlukan untuk mencapai hasil yang diinginkan. Usaha yang dilakukan universitas dengan melaksanakan penelitian institusi tentang tata naskah dinas di universitas lancang kuning, sebagai acuan dalam membuat aturan dan buku pedoman. Agar mendapatkan penjelasan aturan tentang tata naskah dinas. untuk dipahami pejabat dan pegawai selaku pedoman oprasional dalam bekerja. Dengan demikian penulis menyimpulkan bahwa Tata Naskah Dinas di lingkungan universitas lancang kuning belum efisien. 3. Hasil, diamati dari gejala : 
Hasil tidak adanya aturan tentang tata naskah dinas di lingkungan univeritas lancang kuning baik berupa Buku pedoman ataupun peraturan. Hasil lain dari evaluasi kebijakan tata naskah dinas adalah kebijakan setiap unit dalam mengeluarkan naskah dinas saat ini belum standart dan ditemukan masih adanya penggunaan bahas yang tidak baku dalam menulis naskah dinas. Evaluasi kebijakan ini merupakan salah satu langkah dari pengambilan kebijakan. Walaupun pada kenyataannya saat ini belum aturan kebijakan tersebut. Tata naskah dinas seharusnya berlaku untuk semua lingkungan kerja universitas lancang kuning dan fakultas. Dari data yang di dapat disimpulkan aturan tentang naskah dinas dilingkungan universitas lancang kuning belum terlaksana. Adapun ketidak sesuaian pelaksanaan dengan aturan yang dari pembuat kebijakan perlu adanya evaluasi secara berkesinambungan. Penulis berpendapat bahwa persoalan/ ketidaksesuaian naskah dinas dikarenakan oleh beberapa hal : (1) Komunikasi yang kurang intensif antara unit di universitas sebagai pelaksana kebijakan, (2) Penyusunan prosedur pelaksanaan kebijakan tentang tata naskah dinas tidak memiliki payung hukum, (3) kurangnya pemahaman setiap unit dalam menjadalankan bidang yang dijalankan.

4. Dampak, diamati dari gejala :

Dampak yang diterima oleh civitas akademika tentang kebijakan naskah dinas yang belum ada dilingkungan universitas lancang kuning adalah unit kerja mengeluarkan surat yang bukan wewenangnya sehingga terjadi overlaping, ini mengakibtkan tumpang tindihnya kewenangan masing-masing unit. Hal ini juga ditemukan dengan adanya surat tanpa tebusan kerektor dan juga penyimpanan dalam pengarsipan yang kurang baik menyebabkan kinerja kurang baik. Semestinya pengelolaan naskah dinas tertata dengan baik dengan mengarsipkan setiap kegiatan dan melaporkan kegiatan unit secara rinci. Bentuk dari informasi tertulis sebagai alat komunikasi kedinasan yang dibuat dan/atau dikeluarkan oleh pejabat yang berwenang di lingkungan universitas. Dari penjelasan empat fenomena di atas yaitu : input, proses, hasil dan dampak, penulis membuat tabel matriks perencanaan dan realisasi antara empat fenomena yang diharapkan oleh universitas lancang kuning. Berikut tabel matriks perencanaan dan realisasi kebijakan Peraturan Tentang Tata Naskah Dinas di lingkungan universitas lancang kuning :

Tabel 4 Matrik Perencanaan Dan Realisasi

Tata Naskah Dinas Di Lingkungan Universitas Lancang Kuning

\begin{tabular}{|c|c|c|c|}
\hline No & Fenomena & Perencanaan & Realisasi \\
\hline 1 & Input & $\begin{array}{l}\text { a. Sumber daya pendukung dan } \\
\text { bahan-bahan dasar yang } \\
\text { diperlukan untuk melaksanakan } \\
\text { kebijakan tersediakan oleh } \\
\text { universitas sebagai pelaksana } \\
\text { kebijakan } \\
\text { b. Sumber daya manusia dari } \\
\text { pejabat, ketua lemabaga, dosen } \\
\text { dan kepegawai }\end{array}$ & $\begin{array}{l}\text { a.Sumber daya pendukung } \\
\text { dan bahan-bahan dasar } \\
\text { yang diperlukan untuk } \\
\text { melaksanakan kebijakan } \\
\text { tersediakan oleh universitas } \\
\text { sebagai pelaksana kebijakan } \\
\text { b. Sumber daya manusia } \\
\text { dari pejabat, ketua } \\
\text { lemabaga, dosen dan } \\
\text { kepegawai melakukan } \\
\text { Monitoring } \\
\text { Pengembangan }\end{array}$ \\
\hline 2 & Proses & $\begin{array}{l}\text { a. Kebijakan ditujukan untuk } \\
\text { semua unit dilingkungan } \\
\text { universitas lancang kuning } \\
\text { b. Efektivitas kebijakan }\end{array}$ & $\begin{array}{l}\text { a. terstandarnya cara kerja } \\
\text { dan pemahaman terhadap } \\
\text { kewenangan semua unit di } \\
\text { universitas lancang kuning }\end{array}$ \\
\hline
\end{tabular}




\begin{tabular}{|c|c|c|c|}
\hline & & $\begin{array}{l}\text { dilakukan dengan upaya } \\
\text { membuat aturan tentang naskah } \\
\text { dinas agar terstandarisasi di } \\
\text { setiap unit kerja } \\
\text { e. Efisiensi kebijakan dilakukan } \\
\text { dengan memaksimalkan upaya- } \\
\text { upaya } \\
\text { universitas untuk pembuatan } \\
\text { aturan tentang naskah dinas }\end{array}$ & $\begin{array}{l}\text { b. Efektivitas kebijakan } \\
\text { dilakukan dengan upaya } \\
\text { membuat aturan tentang } \\
\text { naskah dinas } \\
\text { e. Efisiensi yang dilakukan } \\
\text { oleh universitas dengan } \\
\text { berbagai upaya untuk } \\
\text { memaksimalakan naskah } \\
\text { dinas dilingkungan } \\
\text { universitas lancang kuning. }\end{array}$ \\
\hline 3 & Hasil & $\begin{array}{l}\text { Terciptanya aturan tentang tata } \\
\text { naskah dinas di lingkungan } \\
\text { universitas lancang kuning }\end{array}$ & $\begin{array}{l}\text { Mengeluarkan aturan atau } \\
\text { buku pedoman tentang tata } \\
\text { naskah dinas melalui } \\
\text { evaluasi terhadap naskah } \\
\text { dinas yang telah ada. }\end{array}$ \\
\hline 4 & Dampak & $\begin{array}{l}\text { Kinerja di semua unit dapat } \\
\text { meningkatkan mutu yang } \\
\text { berkualitas }\end{array}$ & $\begin{array}{l}\text { Peningkatan mutu kinerja } \\
\text { dicapai karena setiap unit } \\
\text { dapat mengelolah naskah } \\
\text { dinas dengan berpedoman } \\
\text { dengan aturan tentang } \\
\text { naskah dinas }\end{array}$ \\
\hline
\end{tabular}

\section{KESIMPULAN}

Berdasarkan kesimpulan di atas, maka berikut ini akan disampaikan beberapa rekomendasi yang sekiranya dapat dijadikan bahan pertimbangan dalam melakukan perbaikan pelaksanaan tata naskah dinas dilingkungan universitas lancang kuning sebagai berikut :

1.Universitas harus secepatnya mengeluarkan kebijakan tentang naskah dinas yang berbadan hukum. Agar kinerja di masing-masing unit dapat meningkat dan terhindari dari tumpang tinding kewenangan.

2.Berdasarkan permen ristek dikti tentang tata naskah dinas bisa menjadi acuan dalam membuat aturan tentang tata naskah dinas dilingkungan universitas lancang kuning, karena secara rinci didalam aturan tersebut telah menjelaskan naskah dinas dari pembuatan lambang, kepala naskah dinas, contoh pembuatan naskah dinas, cap dan format lembar disposisi. belum adanya aturan yang menjelaskan perguruan tinggi swasta padahal pada dasarnya perguruan tinggi swasta juga berada didawah kementrian ristek dikti.

\section{SARAN}

Berdasarkan kesimpulan di atas, maka berikut ini akan disampaikan beberapa rekomendasi yang sekiranya dapat dijadikan bahan pertimbangan dalam melakukan perbaikan pelaksanaan tata naskah dinas dilingkungan universitas lancang kuning sebagai berikut :

1.Universitas harus secepatnya mengeluarkan kebijakan tentang naskah dinas yang berbadan hukum. Agar kinerja di masing-masing unit dapat meningkat dan terhindari dari tumpang tinding kewenangan.

2.Berdasarkan permen ristek dikti tentang tata naskah dinas bisa menjadi acuan dalam membuat aturan tentang tata naskah dinas dilingkungan universitas lancang kuning, karena secara rinci didalam aturan 
tersebut telah menjelaskan naskah dinas dari pembuatan lambang, kepala naskah dinas, contoh pembuatan naskah dinas, cap dan format lembar disposisi.

\section{DAFTAR PUSTAKA}

[1]. Badjuri, Abdulkahar \& Yuwono, Teguh. 2002. Kebijakan Publik Konsep dan Strategi. Undip Press. Semarang.

[2]. Dunn, William N. 1999. Pengantar Analisis Kebijakan Publik, Penyunting Muhadjir Darwin. Edisi Kedua. Cetakan Pertama. Yogyakarta: Gadjah Mada University Press.

[3]. Halilintar, M. P. (2017). Evaluasi Kebijakan Tentang Kerjasama di Universitas X. Jurnal Niara, 10(1), 20-27.

[4]. Islamy, M. Irfan. 2009. Prinsip-prinsip perumusan kebijaksanaan negara. Jakarta: Bumi Aksara.

[5]. Irwanto. 2011. Focused Group Discussion (FGD): Sebuah Pengantar Praktis. Jakarta: Yayasan OborIndonesia.

[6]. Maman, Abdrurrahman. 2009. Analisis, Korealasi, Regresi dan Jalur dalam Penelitian. Bandung: CV Pustaka Setia

[7]. Miles, Matthew B dan Huberman, A. Michael. 1992. Qualitative Data Analysis. New York: Sage Publications, Inc.

[8]. Moleong, Lexy J. 2010. Metode Penelitian Kualitatif. Bandung: PT. Remaja Rosdakarya.

[9]. Nugroho, Riant D., 2010. Otonomi ; Desentralisasi Tanpa Revolusi, Kajian dan Kritik atas Kebijakan Desentralisasi di Indonesia. Jakarta: PT.Elex Media Komputindo.

[10]. Parsons, Wayne. 2005. Publik Policy: An Introduction To The Theory and Practice of Policy Analysis. US: Edward Elgar Publising Company.

[11]. Arsip nasional republik indonesia. 2014. Peraturan kepala arsip republik indonesia No.2 tahun 2014 tentang Pedoman naskah dinas. jakarta

[12]. Kementrian pendidikan dan kebudayaan. 2015. Peraturan Mentri Pendidikan dan Kebudayaan No.74 Tahun 2015 Tentang Tata Naskah Dinas di Lingkungan Kementrian Kebudayaan. Jakarta.

[13].Kementrian Riset, teknologi dan Pendidikan Tinggi. 2015. Peraturan mentri riset, teknologi dan 
pendidikan tinggo No. 20 tahun 2015 tentang tata naskah dinas di lingkungan kementrian riset, teknologi dan pendidikan tinggi

[14]. Sugiyono. 2012. Struktural Equation Modeling: Teori, Konsep dan Aplikasi. Semarang: Badan Penerbit Universitas Diponegoro.

[15].Santoso, Purwo. 2010. Modul Pembelajaran Analisis Kebijakan Publik. Yogyakarta: Universitas Gadjah Mada.

[16]. Usman, et. al. (2010). Tata Naskah Dinas, 1-10.

[17]. Widodo, Joko. 2007. Analisis Kebijakan Publik, Konsep dan Aplikasi Analisis Proses Kebijakan Publik. Malang: Bayumedia Publishing.

[18]. Winarno, Budi. 2012. Teori dan Proses Kebijakan Publik. Yogyakarta: Media Pressindo. 